\title{
Os fraseologismos no português falado no Nordeste brasileiro: unidades fraseológicas para designar a pessoa que não gosta de gastar seu dinheiro
}

\author{
The phraseologisms in Portuguese spoken in the Brazilian Northeast: phraseological \\ units to designate the person who does not like to spend their money
}

\author{
Marcela Moura Torres Paim* \\ Universidade Federal da Babia \\ Salvador, Bahia, Brasil
}

Silvana Soares Costa Ribeiro**

Universidade Federal da Babia

Salvador, Bahia, Brasil

\begin{abstract}
Resumo: Este trabalho apresenta resultados de investigação sobre a fraseologia referente ao campo lexical convivio e comportamento social com base nos dados do Projeto Atlas Linguístico do Brasil (Projeto ALiB). Está vinculado ao Projeto VALEXTRA (Variação lexical: teorias, recursos e aplicações): do condicionamento lexical às constrições pragmáticas, convênio CAPES/COFECUB 838/15 celebrado entre a Universidade Federal da Bahia e a Universidade Paris 13 (Laboratoire Lexiques Dictionnaires Informatique). Busca-se, a partir do material coletado na pesquisa, apresentar um estudo sobre a presença de fraseologismos nas entrevistas dos informantes, oriundos das capitais brasileiras, estratificados por sexo - homem e mulher - faixa etária - de 18 a 30 anos e de 50 a 65 anos - e nível de escolaridade - fundamental e universitário. O termo fraseologismo está sendo aqui concebido como o fenômeno da linguagem que se exprime através de associações sintagmáticas recorrentes (MEJRI, 1997). Parte-se do princípio de que as unidades fraseológicas são combinações de unidades léxicas, relativamente estáveis, com certo grau de idiomaticidade, formadas por duas ou mais palavras, que constituem a competência discursiva dos falantes, em língua materna, segunda ou estrangeira, utilizadas convencionalmente em contextos precisos, com objetivos específicos, como, por exemplo, as respostas que se obtém para a questão referente à pessoa sovina "como se chama a pessoa que não gosta de gastar seu dinheiro e, às vezes, até passa dificuldades para não gastar?" - mão de vaca, mão-fechada, pão-duro e unba de fome. No que diz respeito aos fraseologismos analisados, podem-se fazer algumas considerações: as criações lexicais analisadas contemplam a polilexicalidade; as unidades fraseológicas refletem uma expressão cristalizada, cujo sentido geral não é literal. Demonstra-se também o uso das expressões fraseológicas no território brasileiro relacionado aos fatores sexo, faixa etária e nível de escolaridade. Assim, as designações enfocadas possibilitam a documentação da diversidade lexical do português falado no Brasil, seguindo os princípios da Geolinguística Pluridimensional Contemporânea em que o registro segue os parâmetros diatópicos, diageracionais, diassexuais e diastráticos.
\end{abstract}

Palavras-chave: Fraseologismos. Variação lexical. Variação social. Projeto ALiB.

Abstract: This paper presents research results on the phraseology related to the lexical field, social interaction and social behavior based on the data of the Brazilian Linguistic Atlas Project (ALiB Project). It is linked to the VALEXTRA Project (lexical variation: theories, resources and applications): from lexical conditioning to pragmatic constraints, CAPES / COFECUB 838/15 agreement between the Federal University of Bahia and Paris 13 University (Laboratoire Lexiques Dictionnaires Informatique). From the material collected in the

* Doutora em Língua e Cultura, Professora da Universidade Federal da Bahia. E-mail: mmtpaim@ufba.br ** Doutora em Língua e Cultura, Professora da Universidade Federal da Bahia E-mail: silvanar@ufba.br 
research, we present a study about the presence of phraseologisms in the informants interviews, from the Brazilian capitals, stratified by sex - men and women - age group - from 18 to 30 years and from 50 to 65 years - and level of schooling - fundamental and university. The term phraseologism is here conceived as the phenomenon of language expressed through recurrent syntagmatic associations (MEJRI, 1997). It is assumed that the phraseological units are combinations of lexical units, relatively stable, with a certain degree of idiomaticity, formed by two or more words, that constitute the discursive competence of the speakers, in mother tongue, second or foreign language, conventionally used in specific contexts, with specific objectives, such as the answers to the question of the unworthy person, "what is the name of a person who does not like to spend his money and sometimes even struggles not to spend?"- cow hand, hand-sealed, gingerbread and nail hunger. With regard to the analyzed phraseologies, one can make some considerations: the lexical creations analyzed contemplate the polilexicalidade; the phraseological units reflect a crystallized expression whose general meaning is not literal. It is also demonstrated the use of phraseological expressions in the Brazilian territory related to the factors sex, age group and schooling level. Thus, the focused designations enable the documentation of the lexical diversity of Portuguese spoken in Brazil, following the principles of Contemporary Pluridimensional Geolinguistics in which the record follows the diatopic, diagerational, diassexual and diastrático parameters.

Keywords: Phraseologisms. Lexical variation. Social variation. Project ALiB.

\section{INTRODUÇÃO}

Ao pesquisar acerca da Fraseologia nos dados do Projeto Atlas Linguístico do Brasil (ALiB), é importante observar as distintas possibilidades em que ela pode ser estudada, a depender da corrente teórica seguida. Hoje, no Brasil, existem duas grandes correntes de pesquisadores que se debruçam nos estudos fraseológicos. Uma segue a corrente espanhola, que se dedica a estudar os provérbios e sua constituição, bem como seu uso e compreensão pelos falantes de determinada língua. A outra segue a corrente francesa, adotada por Salah Mejri, e que expande o objeto de estudo da fraseologia para muito além dos provérbios, adotando como principal critério, para a consideração de um elemento como Unidade Fraseológica (UF), o da polilexicalidade.

Inicialmente, será apresentada uma revisão dos conceitos referentes aos estudos fraseológicos na perspectiva francesa. Na sequência, será discutida a relevância de estudar o léxico relacionado ao convívio e comportamento social.

O corpus de análise toma por base as respostas apuradas por meio da aplicação do Questionário Semântico-lexical do Projeto Atlas Linguístico do Brasil (COMITÊ NACIONAL, 2001), campo convívio e comportamento social, no intuito de mostrar a diversidade de unidades fraseológicas no português brasileiro falado observadas em dados referentes às respostas apresentadas pelos informantes das nove capitais nordestinas.

\section{OS FRASEOLOGISMOS NA PERSPECTIVA DA CORRENTE FRANCESA}

A Fraseologia é o termo usado tanto para se referir ao conjunto de fenômenos fraseológicos como para a disciplina que os estuda. Segundo alguns pesquisadores, tratese de uma subdisciplina da Lexicologia, já, para outros, é uma disciplina independente. Logo, na literatura especializada, não existe consenso entre os linguistas no que diz respeito ao status dessa área, à delimitação das unidades que podem ser objeto de investigação e, tampouco, em relação à categorização dessas unidades. 
Considerando-se que a Fraseologia não possui limites claros devido à heterogeneidade, manifestada em maior ou menor amplitude, das unidades lexicais que pode abarcar e que dificilmente contém características definidoras precisas, dependendo do ponto de vista do pesquisador sobre o fenômeno linguístico analisado, partimos, assim, nas considerações apresentadas neste artigo, do entendimento de fraseologismo posto por Mejri (1997) que considera esse campo do estudo da linguagem como um fenômeno que se exprime através de associações sintagmáticas recorrentes que formam as sequences figées, maneira como as unidades fraseológicas são nomeadas nos trabalhos desenvolvidos no campo da Fraseologia francesa.

Mejri se dedica ao estudo do processo de fixação (figement) destas unidades, contemplando vários elementos e elucidando como o processo de fixação de unidades sintagmáticas livres tornam-se unidades sintagmáticas que não podem ser dissociadas. Sendo assim,

O processo de fixação é, em efeito, importante: ele confirma todas as dimensões do sistema linguístico (fonética, sintaxe, morfologia, prosódia, semântica, etc.). Uma sequência (...) comumente empregada em conversas diárias, ilustra perfeitamente o entrelaçamento de todos os níveis que acabamos de mencionar. (MEJRI, 1997, p. 23) (Tradução das autoras.) ${ }^{1}$

Segundo o autor, o processo de fixação (figement) é a operação pela qual as associações sintagmáticas se concretizam, contemplando elementos tais como: verbos suporte, colocações, expressões idiomáticas, pragmatemas, locuções, provérbios, estereótipos. Segundo mostram os estudos desenvolvidos por Mejri (1997), o fato fraseológico não tem recebido a atenção que merece pelas pesquisas em ciências da linguagem, pois os manuais e os tratados de lexicologia têm ignorado esse fenômeno que, por sua complexidade, excede, em muito, o fato lexical (exceto alguns insights muito relevantes em Saussure, Sechehaye e Bally), conforme reafirma o autor.

Ainda de acordo com Mejri (1997), somente os lexicógrafos têm reservado um certo lugar em seus dicionários (cf. entre outros A. Rey e S. Chantreau, 1989). Em Gross (1982), como aponta Mejri (1997), tem-se as primeiras descrições relativamente abrangentes de sequências fixas. O desenvolvimento de pesquisas de ambos, teóricos e aplicados, mostra que este fenômeno está longe de ser marginal, que é bastante sistêmico e que é, na verdade, a expressão de um dos dois princípios que regem a combinação das palavras: a liberdade combinatória e a fixação da combinação.

A Fraseologia pode ser estudada em diferentes áreas (a literatura, a política, a economia), em vários aportes aplicados: o ensino/ aprendizagem das línguas estrangeiras ou a fraseolodidática, o tratamento automatizado das línguas: as bases de dados e a extração automática das sequências fixas; a tradução e o contrastivo; a lexicografia: elaboração de dicionários de fraseologismos (em meio analógico - papel - ou eletrônico).

1 Le figement est en effect important à plus d'une trite: il engage toutes les dimensions du système Linguistique (phonétique, syntaxe, morphologie, prosodie, sémantique, etc.). Une séquence (...) couramment employeé dans la conversation de tous les jours, illustre parfaitement l'imbrication de tous les niveaux que nous venons que mentionner. (MEJRI, 1997, p. 23) 
Dessa forma, o campo fraseológico aparece como um espaço aberto, que perpassa por vários níveis da análise linguística: a língua e o discurso; a sintaxe e o léxico; a lexicologia e a linguística textual; a língua e a cultura; o idiomático e o idiossincrático; as coocorrências e os usos; a análise qualitativa e a análise quantitativa.

Segundo Mejri (2011, p. 195), a Fraseologia é um processo que caracteriza as línguas vivas pelas quais as combinações sintagmáticas perdem totalmente ou parcialmente sua liberdade combinatória para ter um funcionamento e uma significação globais. Como, por exemplo, para dizer sovina, tem-se a possibilidade de dizer: mão de vaca, mão-fechada, pão-duro ou unha de fome.

Para o autor, a Fraseologia é um fenômeno linguístico que abrange vários processos de solidariedade sintagmática, como a fixação que se refere a um processo pelo qual a língua se dota de unidades sintagmáticas cujos componentes formam um bloco e cuja sintaxe interna está em desacordo com a da frase livre correspondente.

Para Mejri (2011, p. 200):

- as unidades fraseológicas podem corresponder a unidades de tradução. Neste caso, seria difícil não considerar esta dimensão lexical;

- $\quad$ este tipo de unidades veicula em sua maioria conotações (inferências) de todos os tipos, incluindo cultural, às quais qualquer tradução deve levar em conta;

- em contextos específicos, como os de fins humorísticos, o conteúdo semântico do texto e sua estrutura geral (sua coerência e sua coesão) se prendem à dimensão fraseológica; isto requer o uso de adaptações ou operacõoes de reescrita que procuram manter o essencial do significado original pretendido, mesmo à custa de alguns ajustes em aspectos do texto original." (Tradução das autoras $)^{2}$

O fraseologismo é uma formação polilexical mais ou menos fixa que corresponde quer ao emprego apropriado das palavras, quer a uma denominação fixa, cuja utilização continua em todos os casos da idiomaticidade de uma dada língua, sendo um segmento linguístico idiomático (com expressões, formas de frases próprias, formas específicas de dizer, maneiras de expressar que se opõem à de outras línguas), cultural (com traços históricos, afetivos e mitológicos da comunidade que compartilha o mesmo idioma) e estilístico (com tipos de discurso, diferentes dialetos, tecnoletos).

Como expõe Mejri (2011), os fraseologismos podem ser classificados em gramaticais e lexicais. Os primeiros, os gramaticais, se referem às locuções que irão equipar todas as línguas para estruturar as frases e os discursos. Incluem-se as locuções conjuntivas e preposicionais, as adverbiais (advérbios de ligação, modalizadores etc.), conectores etc. Os lexicais incluem todas as sequências fixas e as colocações que garantem

2 - les unités phraséologiques peuvent correspondre à des unités de traduction. Dans ce cas, il serait difficile de ne pas tenir compte de cette dimension lexicale;

- ce genre d'unités véhicule le plus souvent des connotations (inférences) de toutes sortes, notamment culturelles dont toute traduction doit tenir compte;

- dans des contextes particuliers, comme celui des usages humoristiques, le contenu sémantique du texte ainsi que sa structuration générale (sa cohérence et sa cohésion) se trouve piégée par la dimension phraséologique; ce qui nécessite le recours à des adaptations ou des opérations de réécriture cherchant à sauver l'essentiel du vouloir-dire initial, même au détriment de certains aspects du texte initial. 
as funções de denominação e de categorização lexicais. São classificados em dois grupos: os fraseologismos da língua geral (comum) e os fraseologismos especializados.

Ainda Segundo Mejri (1997), a profusão terminológica existente no campo de estudo da fraseologia se explica por uma diversidade de origens:

- a tradição gramatical, especialmente nos livros escolares (exemplo típico é locução),

-

a tradição lexicológica e lexicográfica: os termos empregados por Darmesteter,

Rey etc.

- a tradição retórica e estilística: as noções de expressão, de clichê ou de série (Bally),

- $\quad$ os aportes linguísticos modernos: frasema, colocação, pragmatema etc.

Com esse entendimento, consideramos que fazem parte da fraseologia as lexias complexas, formadas por mais de uma unidade lexical - o que caracteriza o termo "polilexicalidade" (MEJRI, 1997), isto é, combinações fixas de significado único, estruturas sintáticas, gramaticais e semânticas, que não podem ser improvisadas e que nem sempre foram pensadas e estruturadas em nossa mente antes de as produzirmos. Parte-se do princípio de que por unidade fraseológica se entende toda e qualquer frase ou expressão cristalizada, cujo sentido geral não é literal, utilizada pelos falantes em situações comunicativas específicas e cujo sentido do todo não resulta da soma do sentido das partes, como se ilustra com mão amarrada e unha de fome, entre outras.

Perseguindo a linha de interesse lexical, este artigo está voltado para a análise de diferentes manifestações da língua portuguesa no Brasil, caracterizadas por usos particulares e específicos de uma área ou de um conjunto de áreas urbanas, geograficamente definidas e linguisticamente identificadas. Analisaremos as unidades fraseológicas documentadas nas capitais nordestinas, com base no que documentam os dados do Projeto Atlas Linguístico do Brasil.

\section{METODOLOGIA ADOTADA PARA A INVESTIGAÇÃO}

Antes de examinar os dados, é necessário aclarar algumas questões concernentes aos procedimentos metodológicos norteadores do trabalho. Neste item, arrolamos os dados gerais do Projeto ALiB, o corpus da pesquisa, dando informações sobre o questionário (recorte campo lexical: convívio e comportamento social e aplicação), as localidades pesquisadas e os informantes selecionados.

O Projeto ALiB tem por meta a realização de um atlas geral do Brasil no que diz respeito à língua portuguesa. Trata-se de um projeto de caráter nacional e em desenvolvimento desde 1996. Nele estão envolvidas, hoje, 14 (quatorze) universidades brasileiras signatárias de um convênio de cooperação interinstitucional firmado entre as instituições. Executar um plano de tão grande amplitude e visibilidade requer empenho e compromisso de muitos pesquisadores brasileiros vinculados a cada universidade participante, o que vem se confirmando ao longo de mais de duas décadas de trabalho da Equipe de pesquisadores do ALiB.

Buscamos, com o Projeto ALiB, o estudo da língua portuguesa no Brasil, para cá transplantada e implantada. Documentar o estado atual da língua portuguesa, cinco 
séculos após a chegada dos portugueses ao Brasil, implica resgatar ou demonstrar, necessariamente: resquícios dos contatos entre língua portuguesa, línguas indígenas e línguas africanas; mudanças sociais operadas na sociedade ao longo deste período (relação entre rural x urbano, escolarização em massa, projetos de povoamento do interior do país e da região centro-oeste) e constituição demográfica do país.

Para concretizar o desejo de produzir o Atlas Linguístico do Brasil, os pesquisadores constituíram um Comitê Nacional, responsável por gerenciar as atividades do empreendimento, tendo como uma de suas metas manter a unidade teórico-metodológica do projeto e garantir a execução das atividades de modo conjunto e coordenado.

Atualmente, a coordenação do Projeto ALiB está sob a responsabilidade de um Comitê Nacional, constituído de 13 (treze) membros assim estruturado: DiretoraPresidente - Suzana Alice Marcelino da Silva Cardoso (Universidade Federal da Bahia), Diretora Executiva - Jacyra Andrade Mota (Universidade Federal da Bahia), Diretores Científicos: Abdelhak Razky (Universidade Federal do Pará); Aparecida Negri Isquerdo (Universidade Federal de Mato Grosso do Sul); Conceição Maria de Araújo (Universidade Federal do Maranhão); Fabiane Cristina Altino (Universidade Estadual de Londrina); Felício Wessling Margotti (Universidade Federal de Santa Catarina); Maria do Socorro Silva de Aragão (Universidade Federal da Paraíba/Federal do Ceará); Marilúcia Barros de Oliveira (Universidade Federal do Pará); Regiane Coelho Pereira Reis (Universidade Federal de Mato Grosso do Sul); Silvana Soares Costa Ribeiro (Universidade Federal da Bahia); Valter Romano (Universidade Federal de Lavras) e Vanderci de Andrade Aguilera (Universidade Estadual de Londrina).

O Projeto ALiB privilegia o estudo da variação espacial ou diatópica, não deixando, entretanto, de considerar a variação social. Documenta-se a fala de diversos informantes em contextos de fala específicos (conversa com perguntas e respostas, relatos de situações pessoais e leitura de texto) de modo a permitir estudar a variação diafásica, a variação diageracional, a variação diagenérica e a variação diastrática.

O ALiB fundamenta-se nos princípios gerais da Geolinguística contemporânea, com a meta de mapear o Brasil com base em dados coletados em 250 pontos, representativos de todas as regiões, e recolhidos, 'in loco', a 1.100 informantes, distribuídos equitativamente por duas faixas etárias — 18 a 30 anos e 50 a 65 anos -, pelos dois sexos e, nas capitais de Estado, em número de 25 (as capitais Palmas, Estado de Tocantins, e Brasília, Distrito Federal, se excluem por questões metodológicas em virtude de serem cidades recém-criadas), por dois níveis de escolaridade - fundamental e universitário - , ficando os demais pontos da rede com apenas informantes do nível fundamental.

Ao se concluir a recolha de dados da rede programada, algumas considerações iniciais já podem ser feitas sobre áreas dialetais brasileiras. O resultado imediatamente esperado do Projeto ALiB é, evidentemente, a produção do próprio atlas, cujos volumes inicias, Introdução e Cartas Linguísticas I, foram publicados em 2014.

O volume 1, com 212 páginas, apresenta a trajetória do Projeto ALiB e descreve os passos metodológicos seguidos. Agregam-se a essa parte a reprodução dos instrumentos metodológicos utilizados e apêndices que complementam a informação. 
Dos instrumentos metodológicos figuram:

- Os questionários linguísticos, apresentados na sua versão inicial uma vez que, no curso da pesquisa algumas alterações ditadas pela experiência em campo foram processadas.

- As fichas de anotação de dados da localidade e do informante.

- O quadro de controle de respostas, instrumento que permitia ao auxiliar de pesquisa, marcando as respostas não obtidas, avaliar, de imediato o rendimento daquele inquérito em função do percentual de respostas dadas e assim poder o inquiridor validálo ou não, porque se tinha estabelecido um teto percentual a partir do qual não se teriam os elementos representativos da localidade.

Nos Apêndices estão a rede de pontos, a lista de pesquisadores do ALiB, a lista de inquiridores e de auxiliares e a relação de Bolsistas de Iniciação Científica e de Apoio Técnico, vinculados a diferentes programas oficiais de financiamento da pesquisa.

O volume 2 apresenta, nas suas 368 páginas, um primeiro conjunto de cartas linguísticas que contemplam resultados, relativos às capitais de estado, no campo da fonética, do léxico e da morfossintaxe, trazendo, em alguns casos, além da visão diatópica, um enfoque diageracional, diassexual e diastrático.

De forma introdutória, figuram 10 cartas que fornecem dados de caráter geral sobre aspectos políticos e geográficos do país, com detalhamento das regiões geográficas nas quais se identificam os pontos da rede em cada uma delas. A essas, seguem-se as cartas linguísticas, propriamente ditas:

- cartas fonéticas que abordam seis fatos descritos e analisados num conjunto de 46 cartas;

- cartas semântico-lexicais, prioritariamente onomasiológicas, mas incluindo duas cartas semasiológicas, num total de 106 cartas que contemplam oito das 14 áreas semânticas constantes do Questionário Semântico-Lexical e focalizam os dados numa perspectiva geral - cartas diatópicas gerais - e com indicação por região - cartas diatópicas regionais;

- cartas morfossintáticas, em número de sete, com dados referentes à flexão de número e de gênero, à distribuição dos pronomes de tratamento e à utilização do verto ter com valor existencial.

Algumas cartas, e na sua maioria, estão acompanhadas de notas que trazem comentários dos informantes e manifestações do inquiridor ou do responsável pela elaboração da carta, com vistas a elucidar aspectos considerados relevantes. Esses tipos de dados que se agregam às cartas constituem-se em fonte significativa para outros tipos de estudo para além dos exclusivamente linguísticos.

Nesta pesquisa, consideraremos fatos relacionados à diversidade diatópica, focalizando os dados obtidos nas nove capitais da região nordeste. 


\section{UNIDADES FRASEOLÓGICAS UTILIZADAS PARA DESIGNAR A PESSOA QUE NÃO GOSTA DE GASTAR SEU DINHEIRO}

O conjunto de unidades fraseológicas registradas nas capitais nordestinas apresenta interesse linguístico-cultural uma vez que possibilita identificar elementos para interpretação da relação do homem com o meio em que vive.

Ao serem inquiridos sobre "Como se chama a pessoa que não gosta de gastar seu dinheiro e, às vezes, até passa dificuldades para não gastar?” (COMITÊ... 2001, p. 32), os informantes pesquisados apresentaram, nove unidades fraseológicas ${ }^{3}$ :

Mão-amarrada - Recife, Inf. 1.

Mão de bebê - Recife, Inf. 1.

Mão de égua - Teresina, Inf. 4, Fortaleza, Inf. 8.

Mão de figa - Aracaju, Inf. 1, 4 e 8, Salvador, Inf. 1, São Luís, Inf. 3 e 8.

Mão de maritaca - São Luís, Inf. 8.

Mão de vaca-Recife, Inf. 2 e 5, Aracaju, Inf. 5, São Luís, Inf. 1, 5, 6, 7 e 8, Teresina, Inf. 4, Fortaleza, Inf. 2, 4, 5 e 8, Natal, Inf. 1 e João Pessoa, Inf. 1, 2, 3, 4, 5 e 7.

Mão-fechada - São Luís, Inf. 1, 6, 7 e 8, Teresina, Inf. 1, 2 e 8 e Fortaleza, Inf. 2 e 6.

Pão-duro - Recife, Inf. 4, Aracaju, Inf. 5, 6 e 8, São Luís, Inf. 1, 3, 4 e 8, Teresina, Inf. 2, 5, 6 e 8, Fortaleza, Inf. 1, 3, 4, 5, 6, 7 e 8, Natal, Inf. 5 e João Pessoa, Inf. 4. Unha de fome - Recife, Inf. 8, Aracaju, Inf. 2, Teresina, Inf. 5 e 6 e João Pessoa, Inf. 2 e 8.

Considerando a forma como se estruturam, identificamos os seguintes tipos, dos quais apresentamos descrição seguida de exemplo ilustrativo.

a) SUBSTANTIVO + prep. DE + SUBSTANTIVO - Ex.: mão de bebê, mão de égua e unba de fome.

b) SUBSTANTIVO + ADJETIVO — Ex.: mão-amarrada, mão-fechada e pão-duro.

Do ponto de vista da distribuição diatópica, é possível visualizar os dados por meio das cartas linguísticas a seguir:

\footnotetext{
${ }^{3}$ Além das unidades fraseológicas registradas e que são alvo da análise aqui trazida, foram documentadas unidades simples tais como casquinha, sovina, avarento ou mesquinho que serão tratadas em outros estudos com os dados coletados pelo Projeto ALiB, a exemplo do Dicionário Dialetal Brasileiro e os próximos volumes do Atlas a serem publicados.
} 


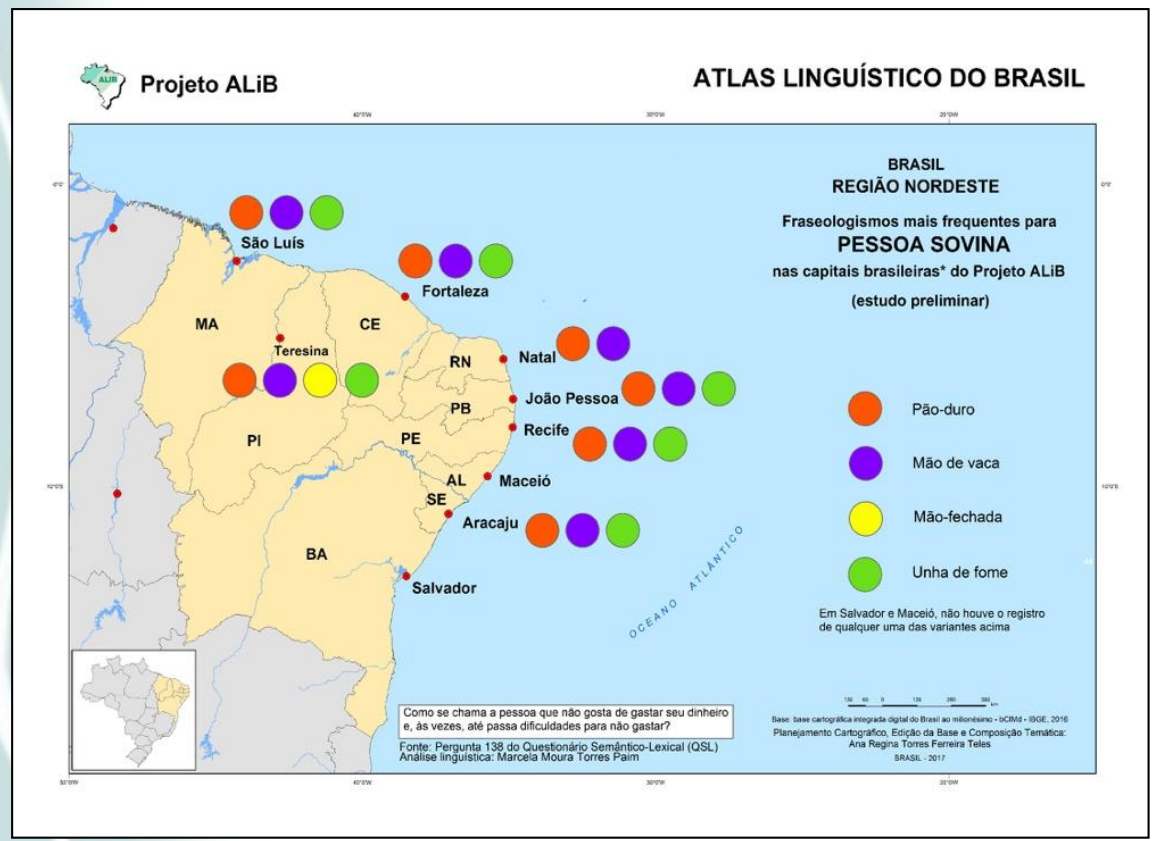

Carta 1: Unidades fraseológicas mais produtivas utilizadas para designar a pessoa que não gosta de gastar seu dinheiro

Fonte: Banco de dados do Projeto Atlas Linguístico do Brasil

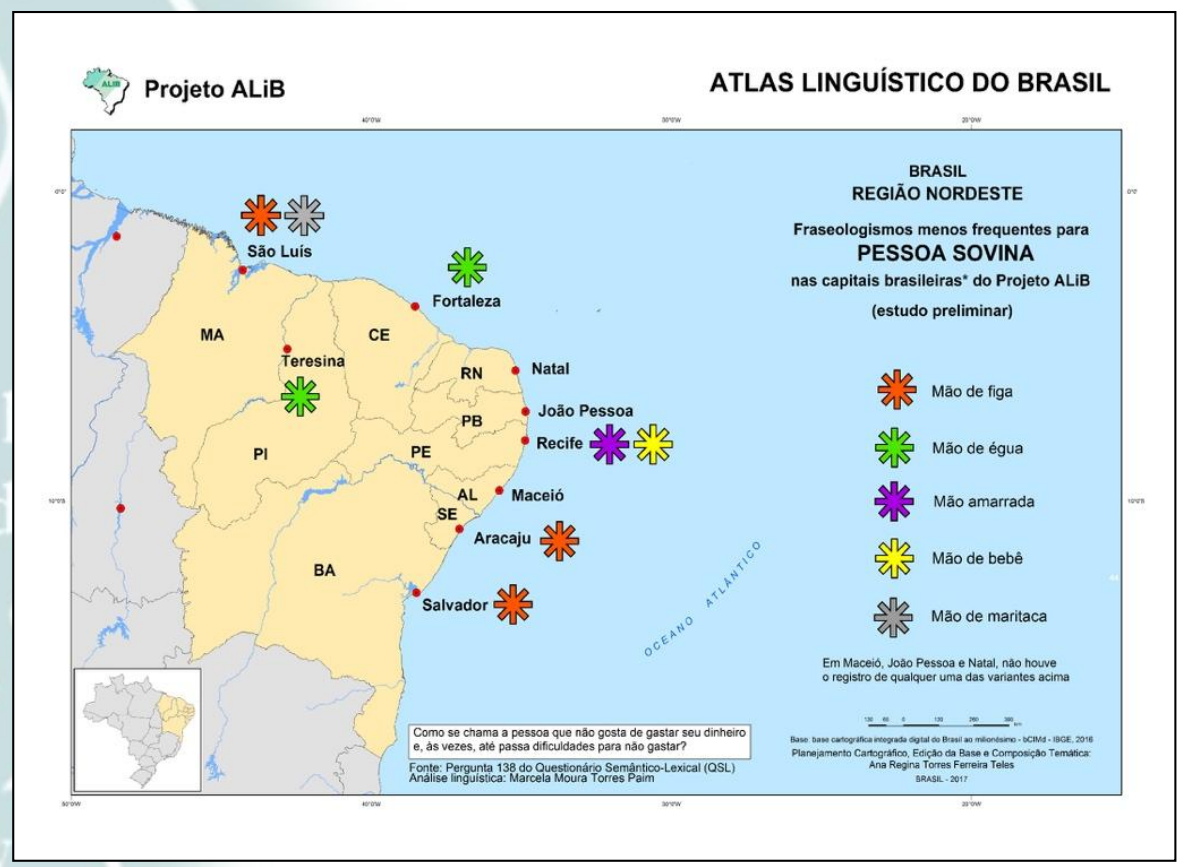

Carta 2: Unidades fraseológicas menos produtivas utilizadas para designar a pessoa que não gosta de gastar seu dinheiro

Fonte: Banco de dados do Projeto Atlas Linguístico do Brasil 
A partir da fala dos informantes é interessante notar o quanto eles conhecem as denominações para pessoa que não gosta de gastar o seu dinheiro. Veja-se no depoimento da informante jovem de Aracaju:

INQ. - Como se diz da pessoa que não gosta de gastar seu dinheiro e até passa dificuldades para não gastar?

INF. - Pão-duro.

INQ. - Tem outro jeito de chamar?

INF. - Mão de vaca. (Aracaju, mulher, faixa I, nível universitário)

Como é possível perceber nos dados levantados, nas capitais estudadas, foram quatro os fraseologismos mais produtivos: mão de vaca (20 ocorrências); mão-fechada (14 ocorrências); pão-duro(a) (21 ocorrências) e unha de fome (6 ocorrências).

\section{PRESENÇA EM DICIONÁRIOS DE LÍNGUA PORTUGUESA}

Também interessou a este artigo entender quantas e de que modo estavam dicionarizadas as unidades fraseológicas mais produtivas na Carta. Para tal, consideramos importante a investigação destas em dicionários de língua portuguesa como Ferreira (1999), Aulete (2006) e Houaiss (2009). Além destes, verificamos a presença destes vocábulos no dicionário eletrônico de fraseologismos, o que foi feito em Xatará (2013).

No intuito de sistematizar a consulta realizada, apresentamos o quadro a seguir:

\begin{tabular}{|l|c|c|c|c|}
\hline $\begin{array}{c}\text { Dicionário } \\
\text { Unidade } \\
\text { fraseológica }\end{array}$ & Ferreira (1999) & Aulete (2006) & Houaiss (2009) & Xatara (2013) \\
\hline Mão de vaca & D & D & DOA & D \\
\hline Mão-fechada & ND & D & D & ND \\
\hline Pão-duro(a) & D & D & D & ND \\
\hline Unha de fome & D & ND & ND & D \\
\hline $\begin{array}{l}\text { D = Dicionarizado; } \\
\text { ND = Não dicionarizado; } \\
\text { DOA = Dicionarizado com outra acepção }\end{array}$ & & \\
\hline
\end{tabular}

\section{Quadro 1: Dicionarização das unidades fraseológicas mais produtivas}

No que diz respeito ao estudo da dicionarização das unidades fraseológicas mais produtivas utilizadas para designar a pessoa que não gosta de gastar seu dinheiro, Ferreira (1999), Aulete (2006) e Xatara (2013) trazem as seguintes informações sobre mão de vaca: 1. Brasileirismo do Nordeste Mocotó; 2. Brasileirismo da Culinária Nordestina Iguaria 
preparada com o mocotó; 3. Expressão popular. Indivíduo mesquinho, avaro. Apenas Houaiss (2009) define como outro sentido, ou seja, relacionado apenas a iguaria da culinária.

A unidade mão-fechada não está dicionarizada em Ferreira (1999) e Xatara (2013), mas se encontra em Aulete (2006) e Houaiss (2009) como "que ou aquele que é sovina; avarento, pão-duro".

A denominação pão-duro só não foi encontrada em Xatara (2013), mas está presente em Ferreira (1999) como: "De pão + duro, da alcunha de um avarento que se alimentava com o pão duro que lhe dava uma padaria". Em Aulete (2006), como "Bras. Pop. Que é excessivamente comedido nos gastos; AVARENTO: Era um marido egoísta e pão-duro" e "Espátula de borracha para raspar alimentos, massas líquidas ou pastosas, do fundo de um recipiente". Em Houaiss (2009) como "Regionalismo: Brasil. Uso: informal. m.q. avarento" e "Espátula de borracha presa a um cabo de madeira ou plástico, a qual se usa para raspar alimentos presos em tachos e afins, sem arranhá-los".

Unha de fome está presente apenas em Ferreira (1999) e Xatara (2013) com a acepção relacionada à avareza.

\section{CONSIDERAÇÕES FINAIS}

O corpus em que se baseia este estudo fornece uma amostra da riqueza fraseológica de que se reveste a língua portuguesa. A interação com a realidade cultural da área em que se inserem as denominações mostra a explícita relação homem-meio.

O estudo das unidades fraseológicas das capitais nordestinas permite, a título de conclusão, as seguintes considerações:

- As construções analisadas contemplam a polilexicalidade.

- Foi recolhido um total de 9 unidades fraseológicas, levantadas através dos inquéritos de 72 informantes em nove capitais.

- Percebe-se que as principais denominações (unidades fraseológicas) utilizadas pelos falantes quando se pergunta sobre "como se chama a pessoa que não gosta de gastar seu dinheiro" foram: mão de vaca, pão-duro(a), mão-fechada e unha de fome.

No que se refere ao registro em obras lexicográficas:

- As unidades fraseológicas mão de vaca e unha de fome não estavam dicionarizadas no dicionário Houaiss (2009); em Ferreira (1999), apenas mão-fechada não estava presente e o fraseologismo mão-fechada não estava presente no dicionário Aulete (2006).

- No dicionário de expressões idiomáticas de Xatara (2013), não foram encontradas as UFs mão-fechada e pão-duro.

Os fraseologismos analisados no português falado no Nordeste refletem a estabilidade no sentido atribuída por Mejri (1997) de relação tão estreita entre os elementos que os leva a perderem o significado primário para adquirirem um novo sentido. 


\section{REFERÊNCIAS}

AUlETE, F. J.; VALENTE, A. L. dos S. Aulete Digital: Dicionário Contemporâneo da Língua Portuguesa. Rio de Janeiro: Lexikon Editora Digital, 2006. Disponível em: http://www.aulete.com.br/. Acesso em: 13 de maio de 2016.

COMITÊ NACIONAL. Atlas Lingüístico do Brasil. Questionários. Londrina: Ed. UEL, 2001.

FERREIRA, A. B. de H. Dicionário Aurélio Eletrônico: século XXI. Rio de Janeiro: Ed. Nova Fronteira e Ed. Lexikon (versão 3.0), 1999.

HOUAISS, A.; VILLAR, M. S. Dicionário Houaiss de Lingua Portuguesa. Elaborado pelo Instituto Antônio Houaiss de Lexicografia e Banco de Dados da Língua Portuguesa S/C Ltda. Rio de Janeiro: Objetiva, 2009.

MEJRI, S. Le figement lexical: descriptions linguistiques et structuration sémantique. Manouba: Publications de la Faculté des Lettres de la Manouba, 1997.

XATARA, C. Dicionário de expressĩes idiomáticas: português do Brasil e de Portugal francês da França, da Bélgica e do Canadá. 2013. Disponível em:

<http://www.deipf.ibilce.unesp.br/pt/index.php>. Acesso em: 25 set 2017. 